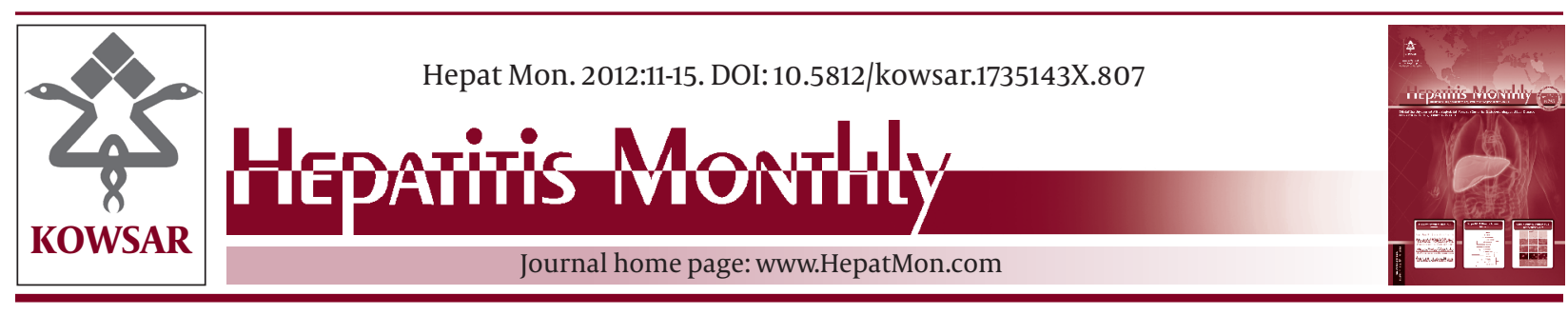

\title{
Association of Hepatitis C Virus With Insulin Resistance: Evidences From Animal Studies and Clinical Studies
}

\author{
Sadaf Badar ${ }^{1}$, Bushra Khubaib ${ }^{1}$, Muhammad Idrees ${ }^{1 *}$, Abrar Hussain ${ }^{1}$, Zunaira Awan ${ }^{1}$, Sa- \\ dia Butt ${ }^{1}$, Samia Afzal ${ }^{1}$, Madeeha Akram ${ }^{1}$, Zareen Fatima ${ }^{1}$, Mahwish Aftab ${ }^{1}$, Sana Saleem ${ }^{1}$, \\ Sara Munir ${ }^{1}$, Bisma Rauff ${ }^{1}$, Mahrukh Naudhani ${ }^{1}$, Liaquat Ali ${ }^{1}$, Muhammaad Ali ${ }^{1}$, Irshad- \\ ul- Rehman ${ }^{1}$ \\ ${ }^{1}$ National Centre of Excellence in Molecular Biology, University of the Punjab, Lahore, Pakistan
}

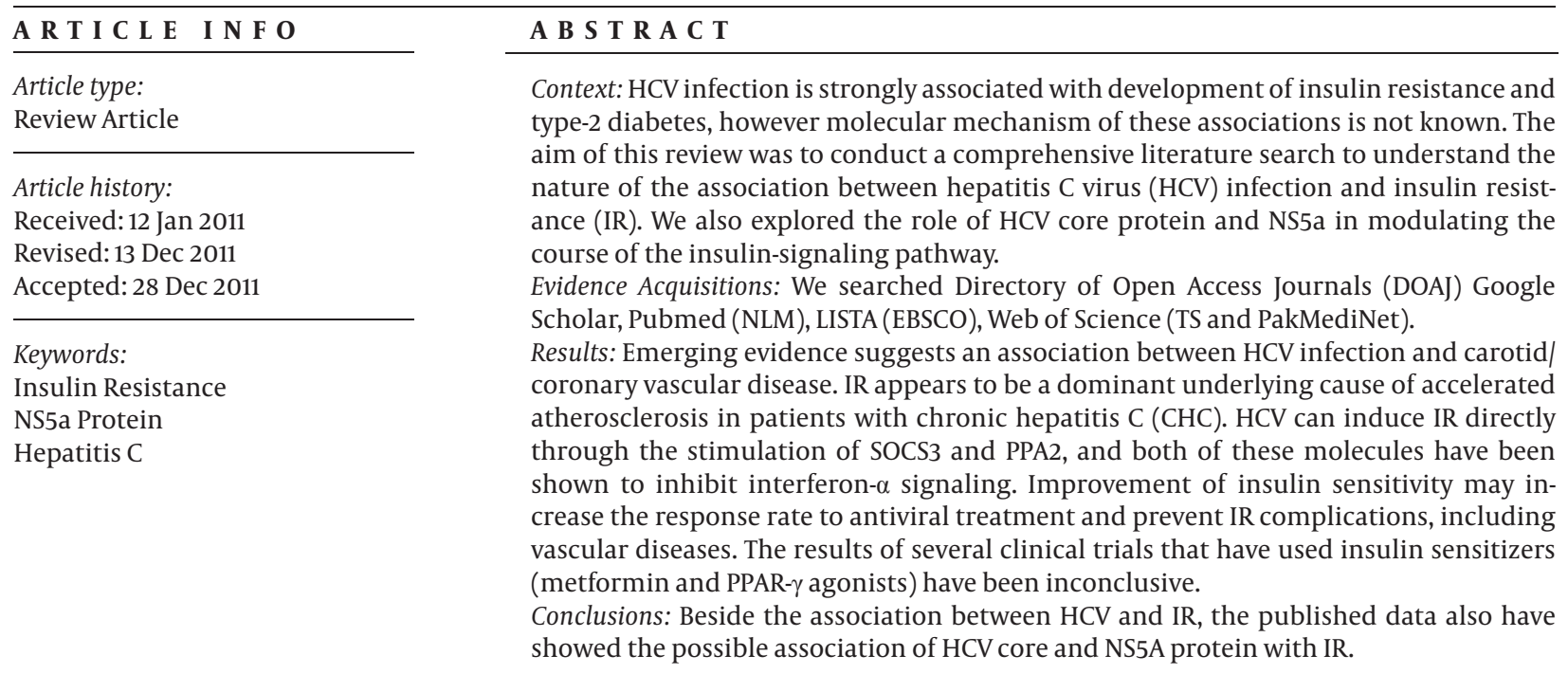

Copyright $\odot 2012$ Kowsar M. P. Co. All rights reserved.

Implication for health policy/practice/research/medical education:

Epidemiological studies have suggested a linkage between insulin resistance/type 2 diabetes and chronic HCV infection however molecular mechanism of this association is not well known. This review focuses on the recent advances in research about these possible pathways in order to bring out some common opinions on how to manage such patients with insulin resistance.

- Please cite this paper as:

Badar S, Khubaib B, Idrees M, Hussain A, Awan Z, Butt S, et al. Association of Hepatitis C Virus With Insulin Resistance: Evidences From Animal Studies and Clinical Studies. Hepat Mon. 2012;11-5. DOI: 10.5812/kowsar.1735143X.807

\section{Context}

Hepatitis C virus (HCV) infection is a serious health problem affecting over 130 million people worldwide

\footnotetext{
* Corresponding author: Muhammad Idrees, National Centre of Excellence in Molecular Biology, 87-West Canal Bank, Road Thokar Niaz Baig Lahore-53700, University of the Punjab, Lahore, Pakistan. Tel: +92-425293141, Fax:+92-425293149, E-mail: idreeskhan96@yahoo.com

DOI:10.5812/kowsar.1735143X.807

Copyright $\odot 2012$ Kowsar M.P.Co. All rights reserved.
}

(1). Approximately $85 \%$ of the HCV-infected population develops severe complications, such as chronic HCV $(\mathrm{CHCV})$, cirrhosis, diabetes, and hepatocellular carcinomas (2-7). CHCV is reported to be the major cause of $50 \%$ to $76 \%$ of all liver cancers globally and also the reason for two-third of all cases of liver transplantation in developed countries (8). It is recognized as a metabolic disease mainly because of its major role in the development of insulin resistance (IR) and type 2 diabetes mel- 
litus (T2DM). The precise nature of association of IR and $\mathrm{CHCV}$ is not completely understood yet; however, it is an established fact that HCV infection enhances IR, which in turn causes liver failure and the development of hepatocellular carcinomas (HCCs) (8) by affecting the response rate for antiviral therapy (9). Furthermore, old age, obesity, severe liver fibrosis, and family history of diabetes are the key risk factors for diabetes mellitus (DM). In non-diabetic HCV-infected patients, IR is associated with stages of liver fibrosis (10). Several HCV-induced pathways lead to fibrosis, inflammation, steatosis, apoptosis, hepatocellular carcinoma, and insulin resistance (11-14). An insight into the mechanisms of liver failure, fibrosis, steatosis, and oxidative stress will help understand the association between HCV pathogenesis and IR (15). This review explores the role of $\mathrm{CHCV}$ in the development of IR and also analyzes the possible association of HCV core protein and NS5A protein with IR.

\section{Evidence Acquisition}

Directory of Open Access Journals (DOAJ) Google Scholar, Pubmed (NLM), LISTA (EBSCO), Web of Science (TS and PakMediNet) were searched with key words "Role of HCV in insulin resistance" "Key observations relevant to insulin resistance", involvement of HCV in the development of insulin resistance" in recent 10 years. Thanks to Higher Education Commission (HEC) Government of Pakistan that we were able to obtain full articles on the reference lists from retrieved documents free of charges. As the information about this topic was rare, small clinical trials and case reports were also included.

\section{Results}

We were able to found 70 research and review articles relevant to this topic directly or indirectly. From the information given in these papers, we drew out following aspects.

\subsection{Insulin}

Insulin, which is synthesized by the pancreatic $\beta$ cells, is the most effective anabolic hormone. It is important for cell growth, cell differentiation, protein synthesis, and maintenance of glucose levels in the body (8). It regulates blood glucose levels by inhibiting the production of liver glucose and by promoting the absorption of glucose in muscle and adipose tissue (16). Insulin stimulates glucose transporter type 4 (GLUT4), which translocates glucose into the plasma membrane, thus increasing cell glucose uptake (8). It is also involved in lipid metabolism, suppressing lipolysis, and promoting lipid synthesis in liver, muscle, and adipose tissues (16). Insulin resistance develops when the concentration of insulin in blood is insufficient to efficiently regulate glucose uptake (17).

\subsection{Insulin Signal Transduction}

Insulin-signaling pathway begins when insulin binds to the extracellular $\alpha$ subunit of insulin receptor substrate (IRS), which further phosphorylates the intracellular tyrosine-kinase domain of the $\beta$ subunit of the insulin receptor. This phosphorylation produces docking sites for many other proteins having SH2 (Src homology 2) domains like phosphatidylinositol 3-kinase (PI3k) (18, 19). PI3k binds to IRS, which phosphorylates phosphatidylinositol 4,5-bisphosphate (PIP2) to phosphatidylinositol triphosphate (PIP3). Interaction of PIP3 with phosphosinositide-dependent kinase 1 (PDK1), in turn, activates protein kinase $\mathrm{B}(\mathrm{AKT} / \mathrm{PKB})$ and protein kinase $\mathrm{C}$ (PKC) (20). Once activated, AKT/PKB decreases the blood glucose levels mainly through 2 pathways. Firstly, by stimulating the phosphorylation of glycogen synthase, which converts surplus glucose into glycogen. Secondly, by suppressing glucose-6-phosphatase and phosphoenolpyruvate carboxykinase, which are involved in gluconeogenesis. Moreover, AKT is important for the localization of GLUT4 in the cell membrane and thus stimulates glucose uptake into skeletal muscle and adipose tissue (8). Insulin resistance arises from the impairment of the abovestated insulin-signaling pathway at multiple steps. One of the most important steps is the phosphorylation of key serine residues including Ser307, Ser318, Ser636, and Ser639 and not phosphorylation of the tyrosine residues for the inhibition of IRS (8).

\subsection{HCV Core Protein and IR}

HCV core protein has been reported to induce overexpression of tumor necrosis factor- $\alpha$ (TNF- $\alpha)$ in the liver of transgenic mice and human hepatoma cell lines (21). TNF is a proinflammatory cytokine that links obesity with IR (22). Over expression of TNF causes insulin resistance through the inhibition of PI3K-mediated activation of insulin receptor substrate 1 (IRS-1) and insulin receptor substrate 2 (IRS-2), and tyrosine phosphorylation of the mitogen-activated protein kinases p42MAPK and p44MAPK. This phosphorylation leads to the impairment of glucose uptake in skeletal muscles (23) and also causes insulin resistance by inhibiting the IKK- $\beta / \mathrm{NF}-\kappa \mathrm{B}$ pathway (24). Expression of core protein in hepatocytes causes an increase in the phospholrylation of ISR-1 at Ser ${ }^{312}$, impairs the activation of AKT at the $\mathrm{Thr}^{308}$ phosphorylation site and also impairs insulin-stimulated glucose uptake (25). HCV core protein is also involved in the inhibition of tyrosine phosphorylation of IRS-1 and production of IRS-2 through a PA28 $\gamma$-dependent pathway (21) However, it appears implausible that the HCV core protein is localized and degraded in the nucleus through a PA28 $\gamma$-dependent pathway as a major mechanism for insulin resistance. HCV core protein may play an important role in the regulation of cellular inflammatory and immune responses through the activation of nuclear factor $\kappa$-light-chain enhancer of activated B cells (NF-kB) $(26,27)$. Activation of NF- $\kappa$ B is involved in the initiation of downstream production of cytokine (interleukin-6 [IL-6]) that leads to insulin resistance $(28,29)$. Increased production of TNF- $\alpha$ and suppressor of cytokine signaling-3 (SOCS-3) in HCV 
infection promotes IR mainly through the inhibition of the insulin receptor and tyrosine phosphorylation of IRS-1 (30). The core protein causes improved production of SOCS-3, which leads to the degradation of IRS-1 and IRS2 (31). Although the effect of different genotypes of HCV on the insulin-signaling pathway is not yet clear, a significant clinical association has been found between the genotypes and IR (8). Over expression of the core protein of genotype $3 \mathrm{a}$ and $1 \mathrm{~b}$ in Huh7 cell line has no effect on the levels of IRS-2, but it reduces IRS-1 protein levels (32). In the case of the core protein of genotype 3a, degradation of IRS-1 is mediated by downregulation of the production of peroxisome proliferator-activated receptor $\gamma$ (PPAR $\gamma$ ) and upregulation of SOCS-7 production; in contrast, genotype $1 \mathrm{~b}$ core protein activates the mammalian target of rapamycin (mTOR) (32).

\subsection{HCV NS5A and IR}

The nonstructural protein 5A (NS5A) of HCV plays a significant role in virus-driven IR. HCV NS5A and increased endoplasmic reticulum stress in HCV infection contributes to overexpression of protein phosphatase 2A (PP2A) $(33,34)$. Christein and colleagues reported that PP2A modulates insulin-signaling pathway by dephosphorylation of AKT, leading to IR in CHC patients (35). In their study, increased levels of PP2A were observed in liver biopsies of HCV patients and also in HCV-protein-expressing livers of transgenic mice. In both the models, insulin signaling was inhibited through PP2A-catalyzed dephosphorylation of AKT (35). Moreover, PP2A can also impair interferon signaling, which is responsible for poor response to interferon therapy for IR in HCV patients (36).

\subsection{Major Disorders Associated With HCV-Induced In- sulin Resistance}

IR is mainly categorized into 2 types-HCV-induced IR and lifestyle-associated IR. Pathogenesis of HCV-induced insulin resistance is different from that of lifestyle-associated IR (37). Cardiovascular diseases are the main cause of death of patients with lifestyle-associated IR $(37,38)$, while HCV-induced IR is responsible for many HCV-associated disorders (37) such as hepatic fibrosis, antiviral drug resistance, steatosis, and hepatocarcinogenesis.

\subsection{Hepatic Fibrosis}

IR plays a pivotal role in accelerating the severity of hepatic fibrosis in HCV-infected patients (31, 37, 39, 40), which is the main characteristic of the early stages of $\mathrm{CHCV}$ infection (10). It is because, IR stimulates the production of free fatty acids and increases lipid deposition in the liver, which, in turn, enhances oxidative stress and consequently results in the development of liver fibrosis (41-43). Moreover, IR is also involved in the proliferation of hepatic stellate cells, which are the main site of deposition of abnormal extracellular matrix in hepatic fibrosis $(44,45)$.

\subsection{Hepatic Steatosis}

Liver steatosis is frequently observed in patients with CHCV infection (46). The rate of incidence of hepatic steatosis in HCV-infected patients is approximately twice than the prevalence rate of steatosis in people with other common liver disorders such as hepatitis B $(47,48)$. One of the major factors responsible for the development of steatosis in HCV-infected patients is the production of triglycerides (49). The core protein of HCV induces aggregation of triglycerides (a low-density lipoprotein) through many mechanisms like activation of fatty acid synthase, downregulation of microsomal triglyceride transport protein, reduction of PPAR $\gamma$, and upregulation of sterol regulatory element-binding protein-1c (49-51). $\mathrm{HCV}$ core protein is also responsible for the production of reactive oxygen species, which, in turn, trigger lipid peroxidation, thus resulting in severe damage to the liver and ultimately to the development of steatosis (49, 52). These findings show a tight association of HCV with hepatic steatosis. Moreover, hepatic insulin resistance mediates the failure of the insulin-signaling pathway, leading to molecular and cellular changes that result in excess accumulation of triglycerides in the hepatocytes (53-55).

\subsection{Hepatocarcinogenesis}

A number of risk factors, such as male sex, age, cirrhotic liver, and alcohol consumption are involved in the development of hepatocellular carcinoma (HCC) in HCV-infected patients (56-59). Recent studies show that IR is another key factor that plays a crucial role in the progression of liver cancer in HCV-infected patients (1, 60, 61 ); however, the precise nature of the association is unknown. IR is responsible for the excessive production of free fatty acids $(62,63)$, which causes increased liver adiposity, thus resulting in a reduction in the adiponectin levels and consequently the development of HCC (64). In addition, fatty acid deposition in hepatocytes causes oxidative stress, which is another risk factor responsible for hepatocarcinogenesis $(60,61)$.

\subsection{Antiviral-Drug Resistance}

Resistance to antiviral treatment is another serious problem associated with HCV-induced IR (37, 65-67). Although, the exact relationship between IR and poor response to antiviral treatment is not clearly understood, IR is known to cause an accumulation of hepatic lipids important for HCV replication $(62,63)$. These droplets activate viral replication and eventually lead to resistance to antiviral treatment not only in HCV genotype 1 but also in genotypes 2 and 3 (68). Moreover, SOCS-3 production is upregulated by the HCV core protein, which is involved in reducing interferon activity. $(69,70)$.

\section{Conclusions}

In this review, we have summarized the association be- 
tween HCV and IR and also have analyzed the possible association of HCV core and NS5A protein with IR. IR is mainly categorized into 2 types-HCV-induced IR and lifestyle-associated IR. The pathogenesis of HCV-induced IR is different from that of lifestyle-associated IR. Cardiovascular diseases are the main cause of death in the case of lifestyle-associated IR, and HCV-associated IR is responsible for many HCV-related conditions such as hepatic fibrosis, antiviral-drug resistance, steatosis, and hepatocarcinogenesis. IR arises from the impairment of the insulin-signaling pathway at multiple steps. Various studies have reported that the core protein of HCV induces IR mainly by modulating the insulin-signaling pathway at the level of IRS. In the case of core proteins of genotype 3a, degradation of IRS-1 is mediated by the downregulation of PPAR $\gamma$ production and upregulation of SOCS-7 production; in contrast genotype 1b's core protein activates mTOR. HCV NS5A and increased endoplasmic reticulum stress in $\mathrm{HCV}$ infection contributes to the overexpression of PP2A, which leads to the impairment of interferon signaling, and is thus responsible for poor response to interferon therapy for treating IR in HCV-infected patients. Since the exact mechanisms of the molecular pathways of HCV-induced IR have not yet been understood, further research is required to determine how virus-induced IR can be managed.

\section{Acknowledgments}

Thanks to free on line digital library offering access to countries appearing in the World Bank's list of "low income economies," plus Djibouti that was used for down load of most of the cited articles using the link: digitallibrary.edu.pk/usflfrmed.html.

\section{Authors' Contribution}

Sadaf Badar and Bushra Khubaib reviewed the literature and wrote the manuscript. Muhammad Idrees edited the manuscript. Abrar Hussain, Zunaira Awan, Sadia Butt, Samia Afzal, Madeeha Akram, Zareen Fatima, Mahwish Aftab, Sana Saleem, Sara Munir, Bisma Rauff, Mahrukh Naudhani, Liaquat Ali, Muhammaad Ali, Irshad-ulRehman helped in literature review. All the authors read and approved the final manuscript.

\section{Financial Disclosure}

None declared.

\section{Funding/Support}

None declared.

\section{References}

1. Alter MJ. Epidemiology of hepatitis C virus infection. World J Gastroenterol. 2007;13(17):2436-41.

2. Alberti A, Vario A, Ferrari A, Pistis R. Review article: chronic hepatitis C--natural history and cofactors. Aliment Pharmacol Ther. 2005;22(Suppl 2):74-8.

3. Asselah T, Rubbia-Brandt L, Marcellin P, Negro F. Steatosis in chronic hepatitis C: why does it really matter? Gut.2006;55(1):12330.

4. Dash S, Haque S, Joshi V, Prabhu R, Hazari S, Fermin C, et al. HCVhepatocellular carcinoma: new findings and hope for effective treatment. Microsc Res Tech. 2005;68(3-4):130-48.

5. Decock S, Verslype C, Fevery J. Hepatitis C and insulin resistance: mutual interactions. A review. Acta Clin Belg. 2007;62(2):111-9.

6. Jeffers L. Hepatocellular carcinoma: an emerging problem with hepatitis C. J Natl Med Assoc. 2000;92(8):369-71.

7. Knobler H, Schattner A. TNF-\{alpha\}, chronic hepatitis $\mathrm{C}$ and diabetes: a novel triad. QJM. 2005;98(1):1-6.

8. Douglas MW, George J. Molecular mechanisms of insulin resistance in chronic hepatitis C. World J Gastroenterol. 2009;15(35):4356-64.

9. Negro F. Insulin resistance and HCV: will new knowledge modify clinical management? J Hepatol. 2006;45(4):514-9.

10. Petit JM, Bour JB, Galland-Jos C, Minello A, Verges B, Guiguet M, et al. Risk factors for diabetes mellitus and early insulin resistance in chronic hepatitis C. J Hepatol. 2001;35(2):279-83.

11. Fartoux L, Poujol-Robert A, Guechot J, Wendum D, Poupon R, Serfaty L. Insulin resistance is a cause of steatosis and fibrosis progression in chronic hepatitis C. Gut. 2005;54(7):1003-8.

12. Pekow JR, Bhan AK, Zheng H, Chung RT. Hepatic steatosis is associated with increased frequency of hepatocellular carcinoma in patients with hepatitis C-related cirrhosis. Cancer. 2007;109(12):2490-6.

13. Lau JY, Xie X, Lai MM, Wu PC. Apoptosis and viral hepatitis. Semin Liver Dis. 1998;18(2):169-76.

14. Bieche I, Asselah T, Laurendeau I, Vidaud D, Degot C, Paradis V, et al. Molecular profiling of early stage liver fibrosis in patients with chronic hepatitis C virus infection. Virology. 2005;332(1):13044.

15. Shulman GI. Cellular mechanisms of insulin resistance. J Clin Invest. 2000;106(2):171-6.

16. Pessin JE, Saltiel AR. Signaling pathways in insulin action: molecular targets of insulin resistance. J Clin Invest. 2000;106(2):165-9.

17. Saltiel AR, Kahn CR. Insulin signalling and the regulation of glucose and lipid metabolism. Nature. 2001;414(6865):799-806.

18. Tamemoto H, Kadowaki T, Tobe K, Yagi T, Sakura H, Hayakawa T, et al. Insulin resistance and growth retardation in mice lacking insulin receptor substrate-1. Nature. 1994;372(6502):182-6.

19. Araki E, Lipes MA, Patti ME, Bruning JC, Haag B, 3rd, Johnson $\mathrm{RS}$, et al. Alternative pathway of insulin signalling in mice with targeted disruption of the IRS-1 gene. Nature.1994;372(6502):18690.

20. Sedaghat AR, Sherman A, Quon MJ. A mathematical model of metabolic insulin signaling pathways. Am J Physiol Endocrinol Metab. 2002;283(5):1084-101.

21. Miyamoto H, Moriishi K, Moriya K, Murata S, Tanaka K, Suzuki T, et al. Involvement of the PA28gamma-dependent pathway in insulin resistance induced by hepatitis $\mathrm{C}$ virus core protein.J Virol. 2007;81(4):1727-35.

22. Greenberg AS, McDaniel ML. Identifying the links between obesity, insulin resistance and beta-cell function: potential role of adipocyte-derived cytokines in the pathogenesis of type 2 diabetes. Eur J Clin Invest. 2002;32 (Suppl 3):24-34.

23. del Aguila LF, Claffey KP, Kirwan JP. TNF-alpha impairs insulin signaling and insulin stimulation of glucose uptake in $\mathrm{C} 2 \mathrm{C} 12$ muscle cells. Am J Physiol.1999;276(5 Pt 1):E849-55.

24. Moon MK, Kim M, Chung SS, Lee HJ, Koh SH, Svovoda P, et al. SAdenosyl-L-methionine ameliorates TNFalpha-induced insulin resistance in 3T3-L1 adipocytes. Exp Mol Med. 2010;42(5):345-52.

25. Banerjee S, Saito K, Ait-Goughoulte M, Meyer K, Ray RB, Ray R. Hepatitis $C$ virus core protein upregulates serine phosphorylation of insulin receptor substrate-1 and impairs the downstream akt/protein kinase B signaling pathway for insulin resistance. $J$ Virol. 2008;82(6):2606-12.

26. Chung YM, Park KJ, Choi SY, Hwang SB, Lee SY. Hepatitis C virus core protein potentiates TNF-alpha-induced NF-kappaB activation through TRAF2-IKKbeta-dependent pathway. Biochem Biophys Res Commun. 2001;284(1):15-9.

27. Yoshida H, Kato N, Shiratori Y, Otsuka M, Maeda S, Kato J, et al. Hepatitis C virus core protein activates nuclear factor kappa Bdependent signaling through tumor necrosis factor receptor- 
associated factor. J Biol Chem. 2001;276(19):16399-405.

28. Arkan MC, Hevener AL, Greten FR, Maeda S, Li ZW, Long JM, et al. IKK-beta links inflammation to obesity-induced insulin resistance. Nat Med. 2005;11(2):191-8.

29. Cai D, Yuan M, Frantz DF, Melendez PA, Hansen L, Lee J, et al. Local and systemic insulin resistance resulting from hepatic activation of IKK-beta and NF-kappaB. Nat Med. 2005;11(2):183-90.

30. Machado MV, Cortez-Pinto H. Insulin resistance and steatosis in chronic hepatitis C. Ann Hepatol. 2009;8 (Suppl 1):S67-75.

31. Kawaguchi T, Yoshida T, Harada M, Hisamoto T, Nagao Y, Ide T, et al. Hepatitis C virus down-regulates insulin receptor substrates 1 and 2 through up-regulation of suppressor of cytokine signaling 3. Am J Pathol. 2004;165(5):1499-508.

32. Pazienza V, Clement S, Pugnale P, Conzelman S, Foti M, Mangia $A$, et al. The hepatitis $C$ virus core protein of genotypes $3 a$ and $1 b$ downregulates insulin receptor substrate 1 through genotypespecific mechanisms. Hepatology. 2007;45(5):1164-71.

33. Christen V, Treves S, Duong FH, Heim MH. Activation of endoplasmic reticulum stress response by hepatitis viruses up-regulates protein phosphatase 2A. Hepatology. 2007;46(2):558-65.

34. Georgopoulou U, Tsitoura P, Kalamvoki M, Mavromara P. The protein phosphatase $2 \mathrm{~A}$ represents a novel cellular target for hepatitis C virus NS5A protein. Biochimie. 2006;88(6):651-62.

35. Bernsmeier C, Duong FH, Christen V, Pugnale P, Negro F, Terracciano L, et al. Virus-induced over-expression of protein phosphatase $2 \mathrm{~A}$ inhibits insulin signalling in chronic hepatitis C.J Hepatol. 2008;49(3):429-40.

36. Duong FH, Filipowicz M, Tripodi M, La Monica N, Heim MH. Hepatitis $C$ virus inhibits interferon signaling through up-regulation of protein phosphatase 2A. Gastroenterology. 2004;126(1):263-77.

37. Kawaguchi T, Sata M. Importance of hepatitis $C$ virus-associated insulin resistance: therapeutic strategies for insulin sensitization. World J Gastroenterol. 2010;16(16):1943-52.

38. Jansson SP, Andersson DK, Svardsudd K. Mortality trends in subjects with and without diabetes during 33 years of follow-up. Diabetes Care. 2010;33(3):551-6.

39. Taura N, Ichikawa T, Hamasaki K, Nakao K, Nishimura D, Goto $\mathrm{T}$, et al. Association between liver fibrosis and insulin sensitivity in chronic hepatitis C patients. Am J Gastroenterol. 2006;101(12):2752-9.

40. Muzzi A, Leandro G, Rubbia-Brandt L, James R, Keiser O, Malinverni $\mathrm{R}$, et al. Insulin resistance is associated with liver fibrosis in non-diabetic chronic hepatitis C patients. J Hepatol. 2005;42(1):41-6.

41. Diehl AM, Li ZP, Lin HZ, Yang SQ. Cytokines and the pathogenesis of non-alcoholic steatohepatitis. Gut. 2005;54(2):303-6.

42. Tilg H, Diehl AM. Cytokines in alcoholic and nonalcoholic steatohepatitis. NEngl J Med. 2000;343(20):1467-76.

43. Sanyal AJ. AGA technical review on nonalcoholic fatty liver disease. Gastroenterology. 2002;123(5):1705-25.

44. Svegliati-Baroni G, Ridolfi F, Di Sario A, Casini A, Marucci L, Gaggiotti $\mathrm{G}$, et al. Insulin and insulin-like growth factor-1 stimulate proliferation and type I collagen accumulation by human hepatic stellate cells: differential effects on signal transduction pathways. Hepatology.1999;29(6):1743-51.

45. Wells RG. Cellular sources of extracellular matrix in hepatic fibrosis. Clin Liver Dis. 2008;12(4):759-68.

46. Rubbia-Brandt L, Quadri R, Abid K, Giostra E, Male PJ, Mentha G, et al. Hepatocyte steatosis is a cytopathic effect of hepatitis $\mathrm{C}$ virus genotype 3.J Hepatol. 2000;33(1):106-15.

47. Czaja AJ, Carpenter HA, Santrach PJ, Moore SB. Host- and diseasespecific factors affecting steatosis in chronic hepatitis C.J Hepatol.1998;29(2):198-206.

48. Thomopoulos KC, Arvaniti V, Tsamantas AC, Dimitropoulou D, Gogos CA, Siagris D, et al. Prevalence of liver steatosis in patients with chronic hepatitis B: a study of associated factors and of relationship with fibrosis. Eur J Gastroenterol Hepatol. 2006;18(3):233-7.

49. Negro F. Mechanisms and significance of liver steatosis in hepatitis C virus infection. World J Gastroenterol. 2006;12(42):6756-65.

50. McPherson S, Jonsson JR, Barrie HD, O'Rourke P, Clouston AD, Powell EE. Investigation of the role of SREBP-1c in the pathogen- esis of HCV-related steatosis. J Hepatol. 2008;49(6):1046-54.

51. Perlemuter G, Sabile A, Letteron P, Vona G, Topilco A, Chretien $\mathrm{Y}$, et al. Hepatitis $\mathrm{C}$ virus core protein inhibits microsomal triglyceride transfer protein activity and very low density lipoprotein secretion: a model of viral-related steatosis. FASEB J. 2002;16(2):185-94.

52. Okuda M, Li K, Beard MR, Showalter LA, Scholle F, Lemon SM, et al. Mitochondrial injury, oxidative stress, and antioxidant gene expression are induced by hepatitis $\mathrm{C}$ virus core protein. Gastroenterology. 2002;122(2):366-75.

53. Petit JM, Minello A, Jooste V, Bour JB, Galland F, Duvillard L, et al. Decreased plasma adiponectin concentrations are closely related to steatosis in hepatitis C virus-infected patients. J Clin Endocrinol Metab. 2005;90(4):2240-3.

54. Hickman IJ, Clouston AD, Macdonald GA, Purdie DM, Prins JB, Ash S, et al. Effect of weight reduction on liver histology and biochemistry in patients with chronic hepatitis C. Gut. 2002;51(1):89-94.

55. Romero-Gomez M, Castellano-Megias VM, Grande L, Irles JA, Cruz M, Nogales MC, et al. Serum leptin levels correlate with hepatic steatosis in chronic hepatitis C. Am J Gastroenterol. 2003;98(5):1135-41.

56. Kenny-Walsh E. Clinical outcomes after hepatitis $C$ infection from contaminated anti-D immune globulin. Irish Hepatology Research Group. N Engl J Med.1999;340(16):1228-33.

57. Wiley TE, McCarthy M, Breidi L, Layden TJ. Impact of alcohol on the histological and clinical progression of hepatitis C infection. Hepatology. 1998;28(3):805-9.

58. Liaw YF, Chen YC, Sheen IS, Chien RN, Yeh CT, Chu CM. Impact of acute hepatitis $C$ virus superinfection in patients with chronic hepatitis B virus infection. Gastroenterology. 2004;126(4):1024-9.

59. Hung $\mathrm{CH}$, Chen $\mathrm{CH}$, Lee $\mathrm{CM}$, Wu CM, Hu TH, Wang JH, et al. Association of amino acid variations in the NS5A and E2-PePHD region of hepatitis $\mathrm{C}$ virus $1 \mathrm{~b}$ with hepatocellular carcinoma. J Viral Hepat. 2008;15(1):58-65.

60. El-Serag HB. Hepatocellular carcinoma: recent trends in the United States. Gastroenterology. 2004;127(5 Suppl 1):S27-34.

61. El-Serag HB. Epidemiology of hepatocellular carcinoma in USA. Hepatol Res. 2007;37(Suppl 2):S88-94.

62. Shimomura I, Matsuda M, Hammer RE, Bashmakov Y, Brown MS, Goldstein JL. Decreased IRS-2 and increased SREBP-1c lead to mixed insulin resistance and sensitivity in livers of lipodystrophic and ob/ob mice. Mol Cell. 2000;6(1):77-86.

63. Miyanari Y, Atsuzawa K, Usuda N, Watashi K, Hishiki T, Zayas M, et al. The lipid droplet is an important organelle for hepatitis $C$ virus production. Nat Cell Biol.2007;9(9):1089-97.

64. Marra F, Bertolani C. Adipokines in liver diseases. Hepatology. 2009;50(3):957-69.

65. Romero-Gomez M. Insulin resistance and hepatitis C. World J Gastroenterol. 2006;12(44):7075-80.

66. Camma C, Bruno S, Di Marco V, Di Bona D, Rumi M, Vinci M, et al. Insulin resistance is associated with steatosis in nondiabetic patients with genotype 1 chronic hepatitis C. Hepatology. 2006;43(1):64-71.

67. Romero-Gomez M, Del Mar Viloria M, Andrade RJ, Salmeron J, Diago M, Fernandez-Rodriguez CM, et al. Insulin resistance impairs sustained response rate to peginterferon plus ribavirin in chronic hepatitis C patients. Gastroenterology. 2005;128(3):63641.

68. Poustchi H, Negro F, Hui J, Cua IH, Brandt LR, Kench JG, et al. Insulin resistance and response to therapy in patients infected with chronic hepatitis C virus genotypes 2 and 3. J Hepatol. 2008;48(1):28-34.

69. Persico M, Capasso M, Persico E, Svelto M, Russo R, Spano D, et al. Suppressor of cytokine signaling 3 (SOCS3) expression and hepatitis $C$ virus-related chronic hepatitis: Insulin resistance and response to antiviral therapy. Hepatology. 2007;46(4):1009-15.

70. Walsh MJ, Jonsson JR, Richardson MM, Lipka GM, Purdie DM, Clouston AD, et al. Non-response to antiviral therapy is associated with obesity and increased hepatic expression of suppressor of cytokine signalling 3 (SOCS-3) in patients with chronic hepatitis C, viral genotype 1. Gut. 2006;55(4):529-35. 